\title{
LACERDA, Paula Mendes. 2015. Meninos de Altamira: violência, "luta" política e administração pública. Rio de Janeiro: Garamond. 328 p.
}

VICTOR CEZAR DE SOUSA VITOR

UNIVERSIDADE DE BRASÍLIA (UNB), BRASÍLIA/DF, BRASIL

HTTPS://ORCID.ORG/0000-0003-I622-7368

Em livro intitulado Meninos de Altamira: violência, "luta" política e administração pública, a antropóloga Paula Lacerda remonta etnograficamente um episódio marcante da criminologia brasileira conhecido como o "caso dos meninos emasculados de Altamira". Como fruto de sua tese de doutoramento em Antropologia Social no PPGAS/MN/UFRJ, tal empreendimento etnográfico buscou compreender a construção do "caso" polêmico em torno de uma série de desaparecimentos, mutilações (ou emasculações), sequestros e assassinatos de crianças, ocorridos no referido município, localizado a 720 km da capital do Pará, entre 1989 e 1993.

A mobilização social empreendida por familiares das vítimas para que os crimes se tornassem dignos de serem investigados, julgados e, assim, reconhecidos como um "caso" - tanto pela perspectiva policial quanto pela perspectiva jurisdicional do referido contexto -, perpassou o sensível esforço de textualização dos testemunhos de dor, sofrimento e luta de familiares por um desfecho que abarcasse o direito à informação como um dos elementos centrais à dignidade do luto.

Lacerda acompanhou a movimentação coletiva em prol da (re)constituição dos fatos a serem investigados criminalmente, percorrendo uma diversidade de versões em disputa, entre familiares das vítimas, população local, inquéritos documentados, mídia local, grupos religiosos, agentes estatais e policiais. No entanto, a conformação do "caso" via trajetória do Comitê em Defesa da Vida da Criança Altamirense foi o principal norteador da pesquisa de campo. Tal norte ganhou destaque junto aos antecedentes históricos da articulação política empreendida pelos familiares das vítimas, remontando a mobilização na Transamazônica, composta predominantemente por ativistas religiosos envolvidos com a Prelazia do Xingu, contexto histórico esse ecoado em seu campo de investigação.

A organização dos capítulos da obra mantém uma interlocução precisa com a constituição da mobilização social de familiares em Altamira, ao reproduzir a divisão da narrativa etnográfica seguindo "o curso pelo qual os crimes foram transformados em uma 'causa' e em um 'caso" (:48). Assim, são marcadores temporais do arranjo interno de sua escrita: "O caso dos meninos emasculados de Altamira” (capítulo um); “'Então nós fomos para a rua!’ - Os sentidos da mobilização” (capítulo dois); 
"Recursos, estéticas e experiências: entre a dor e a política” (capítulo três); "A Instrução Policial” (capítulo quatro); "A 'luta por justiça”" (capítulo cinco); e "A ausência de explicação, o horror e as relações: perspectivas finais".

Entre as principais temáticas levantadas pela obra, estão: a relação intrínseca entre a construção da "causa" (ato político, ativismo e mobilização) e a conformação do "caso" (produto a ser julgado pelo poder público); o agenciamento estigmatizante do descrédito acerca das formas de cuidado materno como elemento de deslegitimação das "denúncias"; a dimensão inexplicável e indizível da barbaridade dos crimes de "emasculação"; a "politização das violências" por familiares e apoiadores como estratégia de não banalização dos crimes; e a linguagem da "dor" e do "sofrimento" como uma das potencialidades de publicização da injustiça e do descaso rotinizado pelo poder público.

Ao atribuir um estatuto epistemológico à noção de "caso" investigativo - explicitando, assim, a produção da verdade no âmbito das práticas de (in)justiça -, um dos pontos-chave de sua etnografia ficou a cargo da constatação de que "sem que houvesse mobilização a partir dos 'crimes', não haveria o 'caso' enquanto tal” (:48); ou, nem mesmo "um processo judicial" como instrumento de legitimação da defesa de direitos.

A maioria das vítimas - crianças e pré-adolescentes entre 8 a 15 anos de idade -, eram filhos de mães solteiras que trabalhavam para complementar a renda familiar. Diante de tais marcadores sociais da diferença e da desigualdade, o delegado que tratou preliminarmente dos "casos", justificou a série de acontecimentos agenciando justamente tais vulnerabilidades como produto de responsabilização das mães, sob o prisma da ausência de "cuidado" com os próprios filhos. Assim, através da produção do “caso" como acontecimentos não cotidianos, Lacerda sinaliza como as famílias buscaram ser levadas a sério perante a Justiça e o Estado brasileiro, necessitando, primeiramente, reivindicar simultaneamente o estatuto de sujeitos de direito de seus filhos e de mães responsáveis.

A discrepância acerca do número de vítimas estabelecido entre os grupos em disputa também se tornou um operador etnográfico para a investigação de controvérsias narrativas em torno do "caso". Desse modo, segundo Lacerda, “o número de vítimas, sempre variante, pode referir-se ao 'caso' como composto por 5 vítimas (aquelas cujos crimes foram a julgamento no processo judicial), 26 (o número referido pelo movimento social formado pelos familiares das vítimas, incluindo desaparecidos e sequestrados), 7 (as vítimas incluídas no inquérito policial que dá origem ao processo judicial), 44 (uma soma entre casos de Altamira e do Maranhão) ou mesmo 14, como vimos na notícia de publicação recente, comentada na nota seis. Sobre esta última contagem, é impossível supor de onde teria partido” (:27).

Ao longo do arranjo do texto, é possível notar que a escrita da antropóloga evidencia seu empenho em interpretar todo o complexo comunicativo (discursos, expressões emocionais e silêncios) que as mulheres, mães ativistas e seus familiares mobilizaram em diversos contextos de disputa por legitimidade e reconhecimento público das atrocidades que constituíram os crimes. Para tanto, Lacerda lança mão de uma pluralidade de linhas teórico-metodológicas ao longo de sua análise. Dentre as principais, estão: pensar o Estado como forma de classificação e de regulação padronizada de sujeitos cujo próprio ente nega reconhecimento e direitos fundamentais, em diálogo com reflexões de Michael Herzfeld e Antônio Carlos de Souza Lima; a formação de ativismos e de sujeitos políticos via construção da denún- 
cia pública de situações de violência, mobilizando Max Weber, Luc Boltanski, John Comerford, Maria Claudia Coelho, Moacir Palmeira, Andréa Zhouri, Antonio Sérgio Alfredo Guimarães, entre outros; a solidariedade como qualificativo moral diante do sofrimento alheio e do morrer, recuperando, respectivamente, as proposições de Susan Sontag e Nancy Scheper-Hughes; especificidades presentes no ativismo de mães e mulheres frente a instituições jurídico-estatais de poder, a partir das considerações de Veena Das, Wendy Brown, Adriana Vianna e Juliana Farias; a produção de diferentes perspectivas acerca de sensos de justiça, inspirado em leituras de Clifford Geertz e de Paul Ricoeur; e o processo de apagamento político de detalhes em experiências de violência, formulado por Rebecca Saunders.

Também merece destaque o empenho da autora em não reduzir a dimensão emocional e irreparável que "o caso dos meninos emasculados" atingiu para as vítimas e seus familiares, ao longo dos anos de construção da demanda por justiça. Tal cautela adotada por Lacerda revela o seu compromisso ético com as formas de classificação e interpretação de suas interlocutoras ativistas sobre os crimes, ao rememorarem as atrocidades cometidas com seus filhos e familiares. Nesse sentido, percebendo as "emasculações" como uma "violência extraordinária", os familiares comunicavam a impossibilidade de reparação pelo mal causado.

Sobre a dimensão jurídica de reparação, o dilema moral em torno de familiares das vítimas receberem ou não benefícios indenizatórios do Estado foi classificado por Lacerda como etnograficamente revelador de percepções dos familiares "sobre si mesmos enquanto 'fracos" (:285). No entanto, tais benefícios as despertavam também como "fortes' e 'persistentes" (ibidem), em um campo de classificações de demandas sociais entre "responsabilidades rotineiras" e "extraordinárias" a serem garantidas pelo Estado.

Levando em consideração o contexto em que as famílias de Altamira eram enquadradas socioeconomicamente, as pensões como "direitos extraordinários" ainda pareciam manter uma vinculação de significação com "direitos rotineiros" que deveriam ser garantias básicas do Estado à população; revelando, assim, haver um vácuo, ou sentimento de incompletude das famílias, acerca de um ideal de justiça não cumprido pelas instituições estatais, ao menos até onde a reparação de um crime "irreparável" poderia alcançar, em termos de políticas públicas.

Por certo, a demanda por justiça empreendida pelas mães e familiares das vítimas atingiu tamanha proporção que não se concluiu com as indenizações. Isso porque manter a "causa" em aberto pôde garantir a legitimação do que se reclamava frente ao Estado. Tal luta ganhou ainda mais legitimidade tomando partido de diversos outros crimes que mantinham algum aspecto em comum com as violações de direitos humanos em Altamira. Assim, a "causa" se institucionalizou como um canal de reivindicação, ao passo em que "a politização das violências dificultava que os crimes fossem banalizados" (:292).

A respeito do lugar que a dimensão do "extraordinário" ocupou na construção do "caso", a antropóloga evidencia que a "hipótese de que os corpos das crianças eram usados em rituais de "magia negra”" (:295) - essa, percebida como uma explicação coerente não apenas para as "autoridades" interessadas em resolver o "caso", mas também para os familiares -, suscitou percepções acerca da ideia do sobrenatural atravessando e se reificando de algum modo no próprio julgamento dos crimes. Apesar da pesquisa de campo indicar os rituais como um dos possíveis aspectos das atrocidades cometidas, mais 
do que tentar procurar uma motivação dos fatos, o estudo buscou evidenciar os marcadores sociais da diferença de classe que emergiram no modo como agentes estatais trataram os acontecimentos "inomináveis", que por sua vez desdobraram-se em práticas ativistas via politização dos crimes.

Por fim, durante a imersão etnográfica, Paula Lacerda conjugou o trabalho de campo com o trabalho de memória das famílias, em torno da contínua mobilização coletiva por justiça ao "caso" dos meninos; articulação essa que, segunda a autora, propiciou aos ativistas e familiares "o contato com o filho que não está mais perto, ou não da mesma maneira” (:300). Assim, em termos de possíveis contribuições oferecidas pela obra à agenda de pesquisas antropológicas, creio que o campo etnográfico apresentado por Lacerda se torna frutífero como um referencial, tendo em vista o acompanhamento da luta de grupos organizados na produção de uma demanda pública perpassada por noções de dor, sofrimento e luto, frente a diversas instâncias estatais de exercício de poder, exigindo desses um esforço retórico e identitário de convencimento moral por reconhecimento.

Victor Cezar de Sousa Vitor é Mestre em Antropologia pela Universidade de Brasilia (UnB) e doutorando nesta mesma instituição. Bolsista CAPES.

RECEBIDO: $08 / 10 / 2018$

APROVADO: $08 / 01 / 2021$ 